\title{
Nível de dano Econômico como Critério para tomada de Decisão No Controle de GuANXuma em SOJ A ${ }^{1}$
}

\author{
Threshold Level as a Criteria for Arrowleaf Sida Control Decision in Soybeans
}

FLECK, N.G. ${ }^{2}$, RIZZARDI, M.A. ${ }^{3}$ e AGOSTINETTO, D. ${ }^{4}$

\begin{abstract}
RESUMO - O nível de dano econômico (NDE) é um conceito simples que integra fatores biológicos e econômicos que se destina a tornar os resultados de uma tomada de decisão lucrativos para o controle das plantas daninhas. O objetivo deste trabalho foi determinar o NDE para infestações de guanxuma (Sida rhombifolia), calculado na base de um único ano, que justifiquem aplicação econômica de medidas para seu controle na cultura da soja. Foram conduzidos experimentos em campo em Passo Fundo e Eldorado do Sul-RS. Os tratamentos constaram de densidades de guanxuma e de épocas de semeadura da soja em relação à dessecação da cobertura vegetal (3, 7 e 11; e 20, 24 e 28 dias após). Os valores de NDE variaram de 2 a 50 plantas $\mathrm{m}^{-2}$, e os de NDE ótimo, de 1 a 6 plantas $\mathrm{m}^{-2}$. Verificaram-se respostas diferentes nas relações de interferência cultura-plantas daninhas entre os ambientes estudados. $\mathrm{O}$ atraso na semeadura da soja em relação à dessecação da cobertura vegetal incrementa o grau de interferência de guanxuma na cultura. Constatou-se que as sementes produzidas pelas plantas daninhas não-controladas, ocorrendo em densidades abaixo do NDE, comprometem a adoção da tomada de decisão de controle com base neste critério.
\end{abstract}

Palavras-chave: Sida rhombifolia, manejo de plantas daninhas, nível de dano econômico ótimo.

ABSTRACT - Threshold level (TL) is a simple concept that integrates biological and economical factors, which it is intended to make profitable the results of a decision process for weed control. The objective of this study was to determine TL for arrowleaf sida (Sida rhombifolia) infestations, calculated on the basis of a single year, that could justify economic application of control measure in soybeans. Field experiments were carried out in Passo Fundo and Eldorado do Sul, RS - Brazil. Treatments consisted of arrowleaf sida densities and soybean seeding times in relation to vegetation cover desiccation (3, 7, and 11; and 20,24, and 28 days after). TL values varied from 2 to 50 plants $m^{-2}$, whereas optimum TL ranged from 1 to 6 plants $m^{-2}$. It was observed different responses for crop-weed interference relations with regard to the different environments evaluated. Delaying soybean seeding in relation to vegetation cover desiccation increases arrowleaf sida interference severity in soybeans. It was noted that seeds produced by non controlled weed plants, at low TL densities, make difficult the control decision process based on this criterion.

Key words: Sida rhombifolia, weed management, optimum threshold level.

\section{INTRODUÇÃO}

Em áreas infestadas por plantas daninhas, a decisão de controlá-las pode ser facilmente justificada em termos econômicos, pois os agricultores estão cientes do efeito negativo de densidades elevadas sobre o rendimento das culturas (Knezevic et al., 1997; Charles et al., 1998). Entretanto, é em baixas densidades de plantas daninhas que eles devem tomar as

1 Recebido para publicação em 5/6/2002 e na forma revisada em 9/12/2002.

Parte da tese do segundo autor para a obtenção do título de Doutor em Fitotecnia.

2 Eng.-Agr., Prof. da Faculdade de Agronomia da Universidade Federal do Rio Grande do Sul - UFRGS, Porto Alegre-RS, Bolsista do CNPq; ${ }^{3}$ Eng.-Agr., aluno do Programa de Pós-Graduação em Fitotecnia da UFRGS, Prof. da Fac. de Agronomia e Medicina Veterinária, UPF, Caixa Postal 611, 99001-970 Passo Fundo-RS, <mail:rizzardi@ upf.tche.br>. ${ }^{4}$ Eng.-Agr., aluno do Programa de Pós-Graduação em Fitotecnia da UFRGS. 
decisões de manejo, tentando calcular os benefícios econômicos de controlá-las, comparativamente ao custo do controle (Knezevic et al., 1997). Nesse sentido, é necessário obter informações sobre a biologia e o manejo de plantas daninhas para que os pesquisadores possam desenvolver sistemas que minimizem os impactos ambientais do controle químico sem sacrificar a lucratividade da produção agrícola (Buhler et al., 1992).

$\mathrm{Na}$ abordagem de controle baseado em nível de dano econômico (NDE), as populações de plantas daninhas são monitoradas durante a estação de crescimento e as medidas de controle são usadas na base de "quando necessário", em vez de serem parte de um programa fixo; assim, o planejamento e a implementação dessas estratégias de manejo requerem a integração de conhecimento técnico e de análise econômica (King et al., 1986).

Na determinação de NDE são utilizados procedimentos matemáticos, na tentativa de representar o sistema real como um sistema de dados, postulados ou de interferências, por meio de uma descrição matemática (Doyle, 1997). Na predição dos efeitos resultantes da interferência cultura-plantas daninhas são utilizados tanto modelos denominados empíricos quanto mecanísticos. Os empíricos são modelos estáticos de regressão que, no caso de plantas daninhas, variam desde a regressão linear simples entre o número ou densidade de ervas e o rendimento de grãos pelas culturas, até o uso de curvas de resposta da cultura, em termos de rendimento, englobando diferentes variáveis (Onofri \& Tei, 1994; Carranza et al., 1995; Doyle, 1997). Os modelos empíricos são caracterizados como modelos puramente matemáticos que, do ponto de vista prático, possuem maior aplicação, porque as perdas de rendimento podem ser previstas como uma função do nível de infestação de plantas daninhas observado logo após a emergência da cultura, além de englobarem basicamente fatores bióticos (Onofri \& Tei, 1994).

O uso de herbicidas pós-emergentes permite ao produtor aplicá-los em áreas onde a população observada de ervas exceda o NDE (Coble \& Mortensen, 1992). Nesse contexto, Lindquist et al. (1998) afirmam que, se a densidade de plantas daninhas dentro de uma unidade de área exceder a densidade equivalente ao NDE, então o produtor pode selecionar um herbicida para aplicar nessa área. O sucesso dos programas de manejo de plantas daninhas relacionados com o uso eficiente de herbicidas depende da habilidade de prever o efeito da espécie daninha sobre o rendimento da cultura. Relações de dano que quantifiquem as perdas no rendimento com base em observações iniciais da infestação das ervas são essenciais para qualquer análise econômica, tanto de curto quanto de longo prazo (Kropff \& Spitters, 1991). Dessa forma, os níveis de dano econômico podem desempenhar função importante em sistemas de manejo integrado de plantas daninhas, constituindo-se numa maneira de auxiliar o produtor a decidir quando o controle destas plantas em sua lavoura apresentará custo eficiente (Weaver, 1991).

O objetivo deste trabalho foi determinar o nível de dano econômico para infestações de guanxuma (Sida rhombifolia), calculado na base de um único ano, que justifiquem a aplicação de medidas para seu controle na cultura da soja.

\section{MATERIAL E MÉTODOS}

Dois experimentos foram conduzidos em campo, na Universidade de Passo Fundo (Cepagro/UPF), em Passo Fundo, região fisiográfica do Planalto Médio do Rio Grande do Sul, e na Universidade Federal do Rio Grande do Sul (EEA/UFRGS), no município de Eldorado do Sul, região fisiográfica da Depressão Central. Um experimento foi conduzido em 1998/99 em Passo Fundo (ambiente 1) e o outro em 1999/00 em Eldorado do Sul (ambiente 2). Os solos das áreas experimentais são classificados como Latossolo Vermelho Distrófico típico e Argissolo Vermelho Distrófico típico, para Passo Fundo e Eldorado do Sul, respectivamente (Embrapa, 1999).

Os tratamentos foram dispostos em esquema fatorial, sem repetições. Nos dois ambientes, os tratamentos representativos do fator A constaram de densidades de guanxuma (Sida rhombifolia), e os do fator B consistiram de épocas de semeadura da soja em relação à data de dessecação da cobertura vegetal existente nas áreas. No ambiente 1 , a semeadura da soja foi realizada 3, 7 e 11 dias após a dessecação 
(DAD); no ambiente 2 isso ocorreu aos 20, 24 e 28 DAD.

As densidades das plantas daninhas foram alocadas aleatoriamente no campo, de acordo com niveis populacionais encontrados naturalmente nas áreas. No ambiente 1 foram utilizadas 15 unidades em cada época, com densidades que variaram de 1 a 60 plantas $\mathrm{m}^{-2}$, perfazendo o total de 45 unidades com infestação. No ambiente 2 utilizaram-se 10 unidades em cada época, com densidades que variaram de 1 a 128 plantas $^{-2}$, totalizando 30 unidades com infestação. Em ambos os experimentos mantiveram-se de quatro a cinco unidades com ausência de plantas daninhas, em cada uma das épocas de semeadura da soja. Cada unidade experimental mediu $6 \mathrm{~m}^{2}$ ( $\left.2 \times 3 \mathrm{~m}\right)$, constando de cinco fileiras de soja espaçadas de 0,4 m.

Os experimentos foram implantados utilizando-se o sistema de semeadura direta, em áreas contendo cobertura vegetal composta por aveia-preta (Avena strigosa) e por algumas espécies daninhas. O manejo da cobertura vegetal foi feito com a mistura dos herbicidas glyphosate (900 g de equivalente ácido ha-1) e 2,4-D (670 g de equivalente ácido $h^{-1}$ ), efetuado por ocasião do florescimento das plantas de aveia-preta. Nos experimentos conduzidos no ambiente 1 foi efetuada uma segunda dessecação com paraquat (300 $\left.\mathrm{g} \mathrm{ha}^{-1}\right)$, três dias antes da primeira época de semeadura da soja, a fim de eliminar as plantas daninhas que não foram controladas com a primeira dessecação e, também, aquelas que emergiram no período entre a primeira e a segunda dessecação. No ambiente 2 , procedeu-se a somente uma dessecação, 20 dias antes da primeira época de semeadura da soja.

Para o ambiente 1, a adubação do solo foi realizada por ocasião da semeadura da soja, por meio da distribuição de $300 \mathrm{~kg} \mathrm{ha}^{-1}$ da fórmula 05-20-30. No ambiente 2, a adubação foi efetuada através da distribuição de $340 \mathrm{~kg} \mathrm{ha}^{-1}$ da fórmula 05-25-25. Nos dois experimentos, utilizou-se o cultivar de soja Embrapa 66, de ciclo médio de desenvolvimento, o qual foi estabelecido na densidade de 400 mil plantas ha ${ }^{-1}$. No ambiente 1 , a semeadura da soja foi realizada em 27 de novembro, 1 e 5 de dezembro; no ambiente 2 , a semeadura da cultura deu-se em 17, 21 e 25 de novembro.
O controle de ervas gramíneas foi obtido com o herbicida clethodim (120 $\mathrm{g} \mathrm{ha}^{-1}$ ), acrescido do adjuvante Assist, usado a 0,5\% volume/volume. Durante a condução dos experimentos foram realizadas suplementações hídricas por meio de irrigações por aspersão, a fim de se garantir adequado desenvolvimento à cultura.

As avaliações das densidades de guanxuma ocorreram 20 dias após a emergência (DAE) da soja, em área de $1,0 \mathrm{~m}^{2}$ por parcela, dividida em dois locais de cada unidade experimental.

O rendimento de grãos da soja foi determinado em área de $3,0 \mathrm{~m}^{2}$ (1,2 x 2,5 m), englobando as três fileiras centrais das parcelas. Por ocasião da pesagem dos grãos foi determinada sua umidade e, posteriormente, os pesos obtidos foram uniformizados para 13\% de umidade.

Aos dados de porcentagens de perda de rendimento de grãos foi ajustado o modelo de regressão não-linear da hipérbole retangular, proposto por Cousens (1985), conforme equação 1 :

$$
\left.\mathrm{P}_{\mathrm{r}}=\left(\mathrm{i}^{*} \mathrm{X}\right) /\left(1+\left((\mathrm{i} / \mathrm{a})^{*} \mathrm{X}\right)\right) \quad \text { (equação } 1\right)
$$

em que $\mathrm{P}_{\mathrm{r}}=$ perda de rendimento (\%); $\mathrm{X}=$ densidade de plantas de guanxuma; $\mathrm{i}=$ porcentagem de perda de rendimento por unidade de planta daninha quando sua densidade se aproxima de zero; e a = porcentagem de perda de rendimento quando a densidade de plantas daninhas tende ao infinito.

$\mathrm{O}$ ajuste do modelo aos dados foi feito usando-se o procedimento Proc Nlin do programa computacional SAS (SAS, 1989). Para esse procedimento, utilizou-se o método de GaussNewton.

O nível de dano econômico foi calculado com base na equação 2 , proposta por Lindquist \& Kropff (1996):

$$
\left.\mathrm{NDE}=\mathrm{C} /\left(\mathrm{R}^{*} \mathrm{P} *(\mathrm{i} / 100) * \mathrm{E}\right) \quad \text { (equação } 2\right)
$$

em que $\mathrm{NDE}=$ nível de dano econômico (plantas $\mathrm{m}^{-2}$ ); $\mathrm{C}=$ custo do controle (custos do herbicida e da aplicação, em dólares ha-1); $\mathrm{R}=$ rendimento de grãos de soja $\left(\mathrm{kg} \mathrm{ha}^{-1}\right) ; \mathrm{P}=$ preço da soja (dólares $\mathrm{kg}^{-1}$ de grãos); i = porcentagem de perda de rendimento da soja por unidade de planta daninha quando sua densidade se aproxima de zero, obtido pela equação 1; e E = nível de eficiência do herbicida (\%). 
No cálculo do NDE foram introduzidos alguns cenários relacionados aos fatores $\mathrm{C}$, $\mathrm{R}, \mathrm{P}$ e E da equação 2. Para o fator C, considerou-se como faixa de custo do controle 20,00 a 40,00 dólares ha-1, com base no preço médio pago pelo produtor nos últimos cinco anos por herbicidas recomendados para o controle de ervas dicotiledôneas na cultura da soja, acrescido do custo de aplicação destes. Os rendimentos de grãos da soja utilizados no cálculo do NDE foram de 1.500, $2.500 \mathrm{e}$ $3.500 \mathrm{~kg} \mathrm{ha}^{-1}$, estabelecidos segundo níveis diferenciados de potencial de produtividade derivados de situações de baixa, média e alta tecnologias, respectivamente. Como referencial, o rendimento médio obtido nos últimos 10 anos no Estado do Rio Grande do Sul foi de $1.770 \mathrm{~kg} \mathrm{ha}{ }^{-1}$. Para o fator P, foi utilizada faixa de valores da soja entre 17,00 e 20,00 dólares $100 \mathrm{~kg}^{-1}$ de grãos, tendo em vista que, nos últimos 10 anos, os preços médios recebidos pelos produtores, nos meses de menor e maior valores, foram de 17,60 e 19,60 dólares $100 \mathrm{~kg}^{-1}$, respectivamente. Os valores para eficiência do herbicida (E) foram selecionados na faixa de 80 a $100 \%$ de controle.

O nível de dano econômico ótimo (NDEO), o qual considera o impacto da produção de sementes pelas plantas daninhas mantidas na área, foi calculado com base na equação 2 . No cálculo, substituíram-se os valores do parâmetro "i" da equação 2 por outro parâmetro (Rizzardi, 2002), o qual reflete a variação na produção de sementes pelas plantas daninhas em resposta à densidade.

\section{RESULTADOS E DISCUSSÃO}

Nas diferentes situações investigadas, o grau de interferência causado em soja pela presença de guanxuma foi menos intenso nas semeaduras realizadas mais próximo à dessecação da cobertura vegetal, principalmente no ambiente 1 (Figura 1). Os valores estimados para o parâmetro "i” foram de 0,$24 ; 0,73$; e 2,2 nas respectivas semeaduras de 3,7 e 11 DAD no ambiente 1 , e de 1,01; 0,69; e 1,96 nas semeaduras efetuadas aos 20, 24 e 28 DAD no ambiente 2 .

Os valores de NDE variaram de 2 a 50 plantas $\mathrm{m}^{-2}$ no ambiente 1 (Figura 2) e de 3 a 17 plantas $\mathrm{m}^{-2}$ no ambiente 2 (Figura 3). Os diferentes intervalos estabelecidos entre dessecação da cobertura e semeadura da soja entre os ambientes também influenciaram as diferenças constatadas nos NDEs.

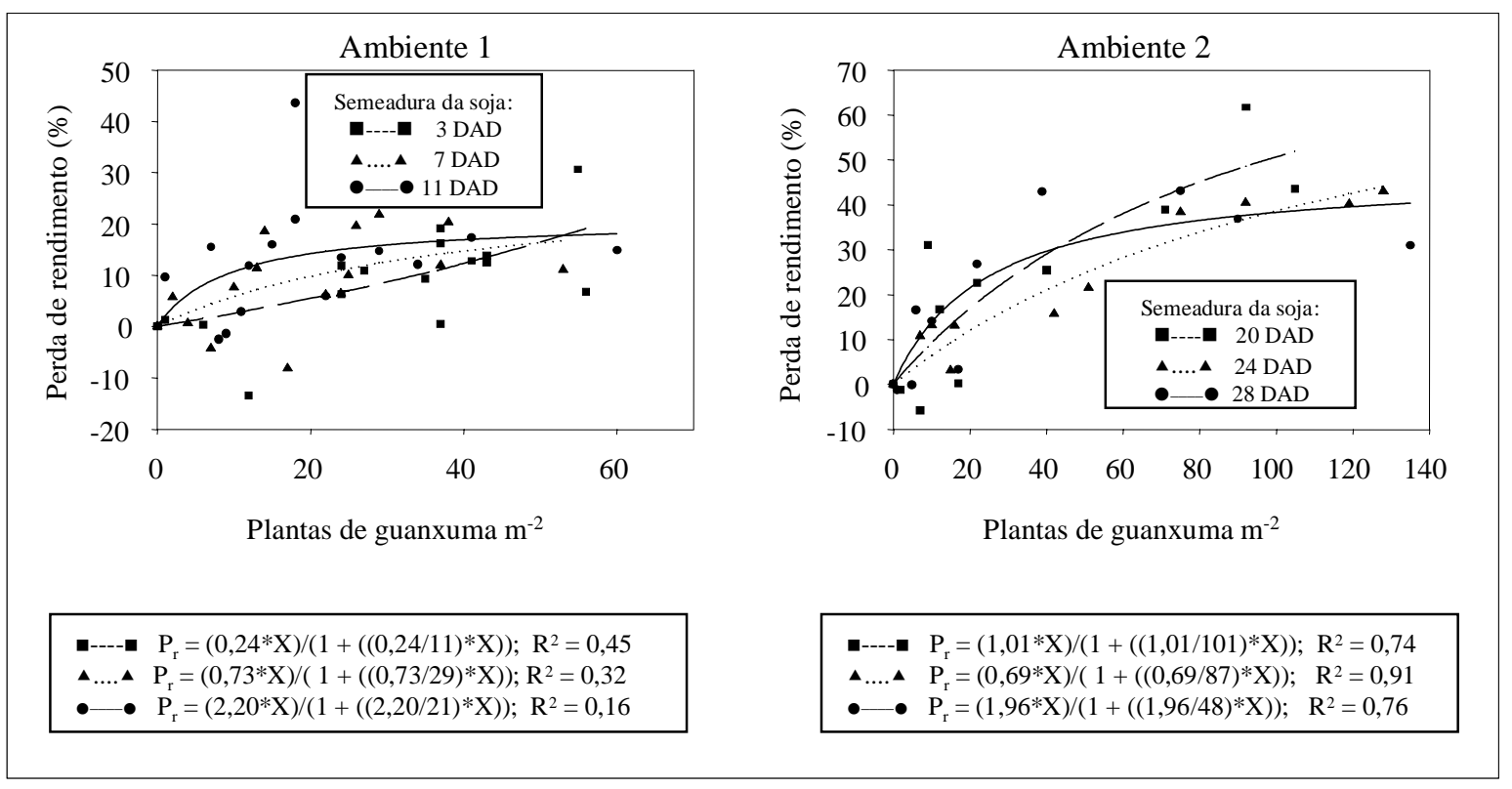

Figura 1 - Perda de rendimento $\left(\mathrm{P}_{\mathrm{r}}\right)$ de grãos de soja em função de densidades de plantas de guanxuma e de épocas de semeadura da soja após dessecação da cobertura vegetal, Passo Fundo-RS, 1998/99 (ambiente 1) e Eldorado do Sul-RS, 1999/00 (ambiente 2). (DAD = dias após dessecação). 


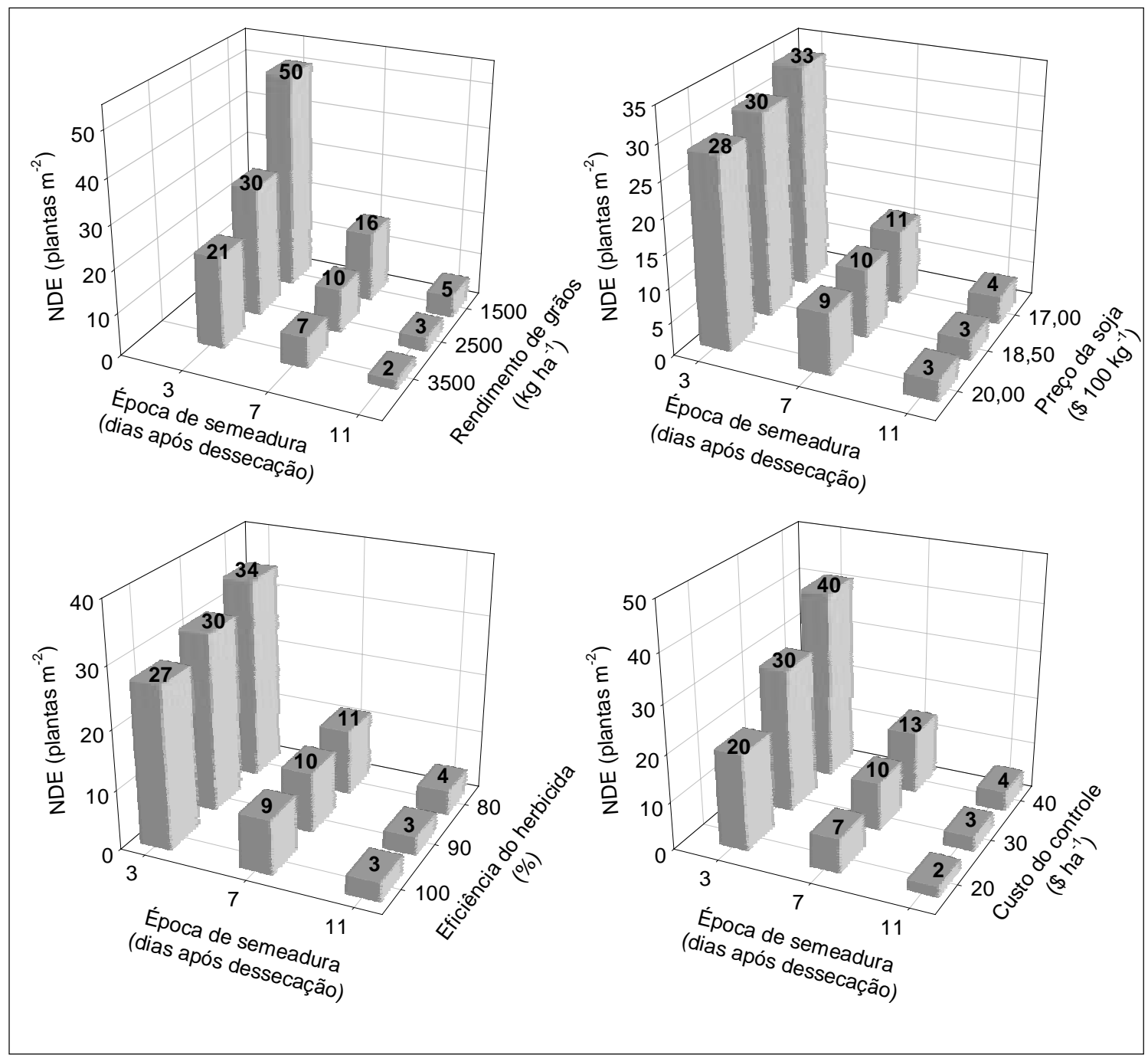

Figura 2 - Nível de dano econômico (NDE) de guanxuma em soja em função da época de semeadura da cultura após dessecação da cobertura vegetal, rendimento de grãos e preço da soja e eficiência e custo do controle químico da planta daninha, em Passo Fundo-RS, 1998/99 (ambiente 1).

Em relação ao efeito de épocas de semeadura da soja nos NDEs no ambiente 1, constata-se que, à medida que se atrasou a semeadura em relação à dessecação da cobertura vegetal, diminuíram os valores de $\mathrm{NDE}$ (Figuras 2 e 3), o que é explicado pelo efeito desse fator na função dano das ervas, caracterizado pelas alterações verificadas nas estimativas do parâmetro "i” (Figura 1). No ambiente 2, o período mais longo entre dessecação da cobertura e semeadura da soja confundiu o efeito de épocas de semeadura, em que os NDEs foram maiores na semeadura de $24 \mathrm{DAD}$ do que na de $20 \mathrm{DAD}$, porém eles diminuíram acentuadamente na semeadura efetuada aos $28 \mathrm{DAD}$ (Figura 3). Os NDEs para guanxuma no ambiente 2, em geral, aumentaram em até $50 \%$ da semeadura aos 20 para 24 DAD, mas reduziram em até $50 \%$ da semeadura de 20 para 28 DAD. Apesar desses resultados contraditórios, mantém-se a tendência de que o número de dias entre o manejo da cobertura vegetal e a semeadura da soja influencia decisivamente a intensidade de interferência cultura-plantas daninhas.

Para Dieleman et al. (1996), a época de emergência de Amaranthus spp. mostrou ser 
importante na análise econômica devido à influência que teve sobre a função dano. O atraso na emergência dessa planta daninha, em relação à soja, aumentou o nível de dano. Dessa forma, a época relativa de emergência é uma variável crítica a se incorporar na função dano para definir com precisão o nível populacional da planta daninha a ser controlada.

A escolha de um herbicida que apresente menor eficiência indica serem necessárias populações mais elevadas de plantas daninhas para justificar um controle econômico (Figuras 2 e 3). A integração dos efeitos da eficiência do herbicida e do custo do controle pode ser obtida por meio da análise de trabalhos com doses de herbicidas (Dieleman et al., 1996).

As doses recomendadas para herbicidas usualmente são definidas visando alcançar grau de controle eficiente sob ampla variação de condições de ambiente e de manejo (Devlin et al., 1991). Algumas vezes, com adequado manejo e/ou sob certas condições ambientais, as doses dos herbicidas podem ser consideravelmente reduzidas e, ainda assim, controlar com eficiência as plantas daninhas (Devlin et al., 1991; Klingaman et al., 1992). Nesse sentido,

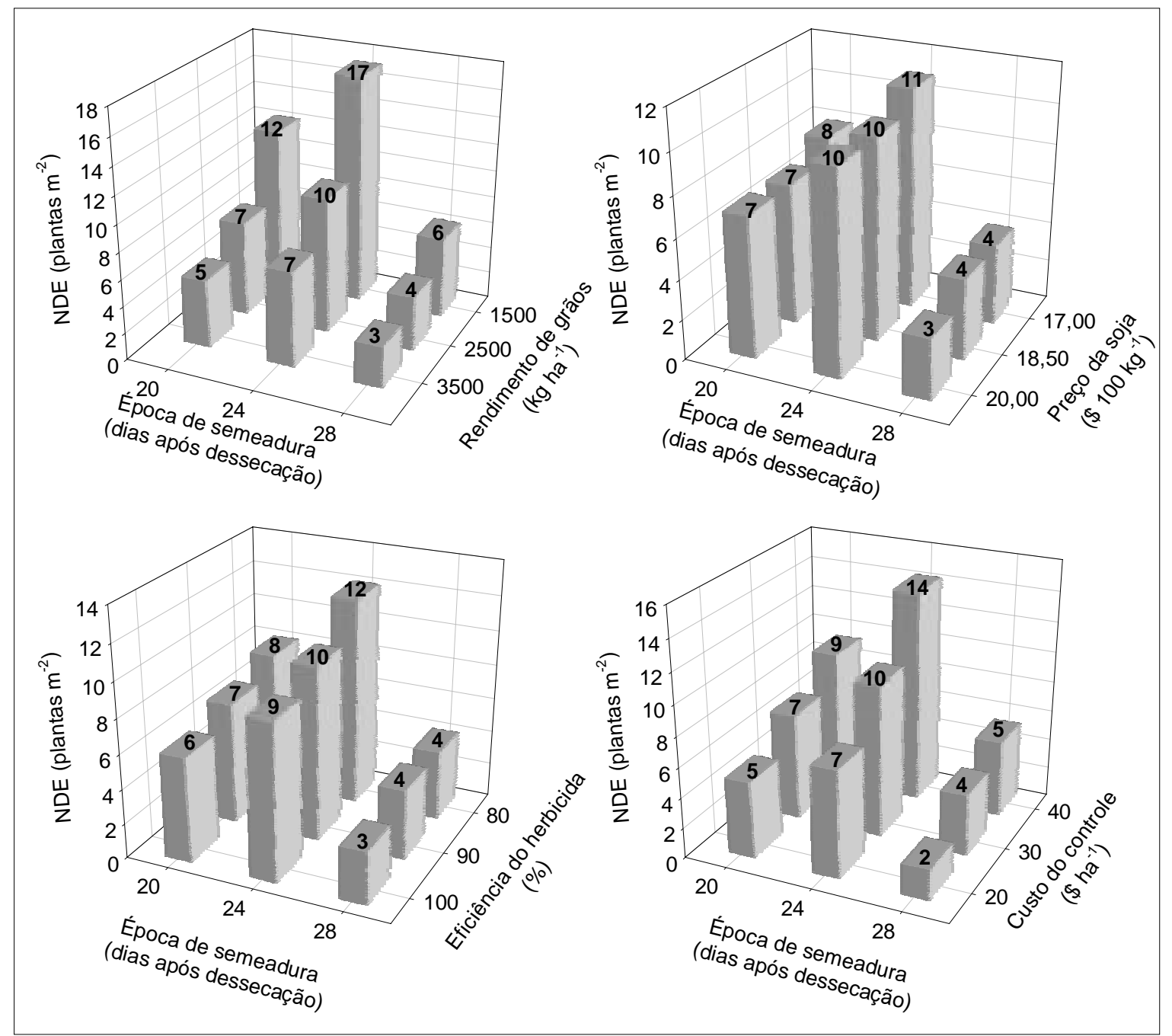

Figura 3 - Nível de dano econômico (NDE) de guanxuma em soja em função da época de semeadura da cultura após dessecação da cobertura vegetal, rendimento de grãos e preço da soja e eficiência e custo do controle químico da erva, em Eldorado do Sul-RS, 1999/00 (ambiente 2). 
Dieleman et al. (1996) enfatizam que, dependendo do nível desejado de controle de plantas daninhas, poderia ser escolhido um herbicida que as eliminasse totalmente (usando a dose recomendada ou biologicamente eficaz), ou um que simplesmente reduzisse o crescimento delas e, dessa forma, neutralizasse sua interferência na cultura (dose ótima). Ao compararem a dose recomendada com a dose ótima, tanto Dieleman et al. (1996) quanto Bosnic \& Swanton (1997) constataram que doses economicamente ótimas foram muito menores do que as doses registradas em rótulo. Para os autores, doses economicamente ótimas asseguram maximização do lucro e reduzem a quantidade de herbicida aplicada no ambiente. No entanto, a utilização de doses reduzidas pode acabar selecionando populações de plantas daninhas resistentes a herbicidas (Czapar et al., 1997).

Qualquer aumento nos custos do herbicida ou de sua aplicação significa acréscimos no NDE - outros fatores permanecendo constantes (Figuras 2 e 3). Nesse aspecto, vale lembrar que, para baixas populações de plantas daninhas, geralmente aquelas em que se situam os NDEs, as perdas de rendimento elevam-se de modo aproximadamente linear. Isso significa que, para pequenas alterações nos NDEs, a possibilidade de ocorrer aumentos relevantes na perda de produtividade é bem grande. Todavia, aumentos no rendimento da cultura, no valor do produto colhido, na eficiência de controle ou na perda de rendimento da cultura por unidade de erva ocasionam redução no NDE.

Três dos fatores envolvidos no cálculo de NDE (custo do herbicida, custo de sua aplicação e valor da cultura por unidade comercializada) podem ser estimados com relativa precisão pelos produtores. Entretanto, potencial de rendimento da cultura, perda proporcional por unidade de planta daninha e eficácia do herbicida são fatores mais difíceis de estimar com precisão devido à variabilidade associada com condições do ambiente, conjunto de espécies daninhas, tamanho das ervas presentes e efeitos dos sistemas de cultivo sobre elas (Coble \& Mortensen, 1992; McDonald \& Riha, 1999; Pester et al., 2000). Portanto, uma dificuldade em se usar a abordagem de NDE é que o produtor, ao confrontar-se com a decisão de manejo, não conhece antecipadamente qual será o rendimento da cultura livre de plantas daninhas, podendo estimá-lo apenas com base no histórico da lavoura e na meta de rendimento para a qual a cultura é manejada.

O cálculo do NDEO somente foi possível de realizar no ambiente 2 , o qual variou de 1 a 10 plantas $\mathrm{m}^{-2}$ (Figura 4). Os valores de NDEO foram aproximadamente 2,6 vezes menores do que os de NDE. No ambiente 1, não foi possível calcular o NDEO, pois não se obteve relação entre produção de sementes e densidade de guanxuma.

Não controlar uma população de plantas daninhas que se situe próximo do nível de dano pode definir ou não se será excedido um nível de dano em anos subseqüentes (Bauer \& Mortensen, 1992; Jones \& Medd, 2000). Por isso, o impacto de populações de ervas, mesmo abaixo do nível de dano, sobre o banco de sementes no solo tem sido objeto de muita preocupação. Foi demonstrado que o NDE é consideravelmente menor quando são levados em consideração os efeitos das plantas daninhas sobre as culturas em mais do que uma estação (Black \& Dyson, 1997).

Os retornos anuais de sementes ao solo demandarão altos níveis de investimento para controle de plantas daninhas nas culturas estabelecidas seqüencialmente na área. A produção

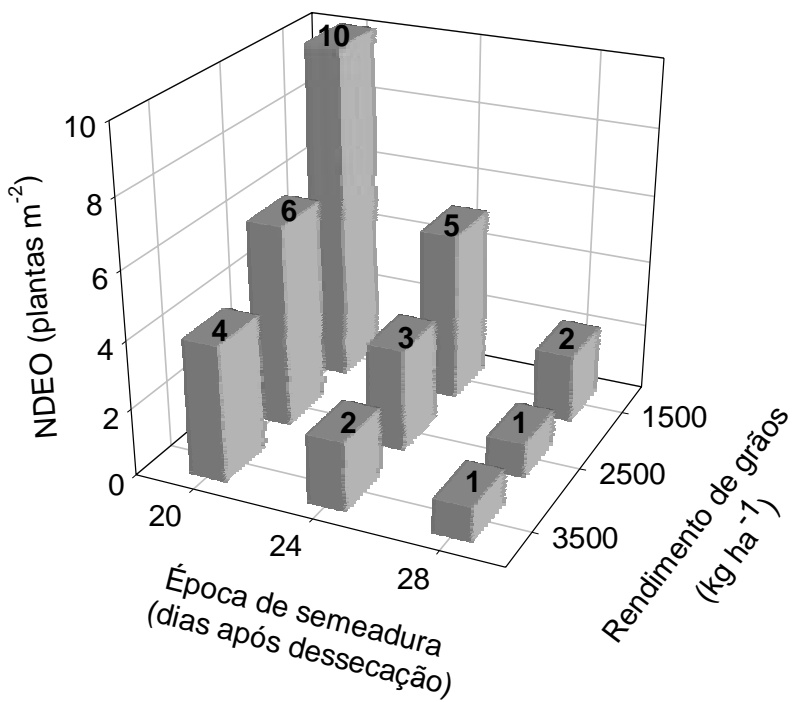

Figura 4 - Nível de dano econômico ótimo (NDEO) de guanxuma em soja em função da época de semeadura da cultura após dessecação da cobertura vegetal e do potencial de rendimento de grãos da soja, em Eldorado do Sul-RS, 1999/00 (ambiente 2). 
de sementes por plantas daninhas, embora não inviabilize a adoção da tática de NDE, poderá diminuir significativamente o valor do limiar de dano baseado em um único ano e que não leva em consideração a produção de sementes (Bauer \& Mortensen, 1992). Assim, a tomada de decisão de controle, considerando-se apenas o NDE, deverá ser acompanhada de um programa consistente de manejo integrado de plantas daninhas que minimize os efeitos de populações residuais de plantas daninhas não-controladas, como adoção da prática de rotação de culturas, arranjo apropriado de plantas, uso de cultivares mais competitivos, supressão da produção de sementes e seleção de doses de herbicidas eficientes no controle de plantas daninhas.

Outro aspecto que dificulta a adoção do conceito de NDE no manejo de plantas daninhas associa-se às expectativas dos produtores em relação ao controle das ervas, os quais geralmente consideram aceitável somente controle entre 90 e 100\% (Czapar et al., 1997). Segundo os autores, embora baixos níveis de competição por plantas daninhas possam não afetar significativamente os rendimentos finais, a possibilidade de ocorrerem atrasos no momento da colheita e os riscos de se verificarem problemas com o próprio equipamento de colheita são fatores importantes considerados pelos produtores para não adotarem o conceito na prática.

Com este trabalho pode-se concluir que a variação na época de semeadura da soja em relação à dessecação da cobertura vegetal modifica a decisão de controle de plantas daninhas, em que semeadura realizada mais próximo ao manejo da cobertura permite adoção de controle sob maiores NDEs para guanxuma. Aumentos na perda de rendimento por unidade de planta daninha, no rendimento da cultura, no valor do produto colhido e na eficiência do herbicida diminuem o NDE, tornando potencialmente mais necessário o controle, ao passo que aumento no custo do controle das plantas daninhas faz elevar o NDE.

\section{AGRADECIMENTOS}

Ao CNPq (Proc. no 460789/00-7) e à Fapergs (Proc. no 00/0228.9), pelo apoio financeiro na execução do trabalho.

\section{LITERATURA CITADA}

BAUER, T. A.; MORTENSEN, D. A. A comparison of economic and economic optimum thresholds for two annual weeds in soybeans. Weed Technol., v. 6, n. 1, p. 228-235, 1992.

BLACK, I. D.; DYSON, C. B. A model of the cost of delay in spraying weeds in cereals. Weed Res., v. 37, n. 3, p. 139146, 1997.

BOSNIC, A. C.; SWANTON, C. J. Economic decision rules for postemergence herbicide control of barnyardgrass (Echinochloa crus-galli) in corn (Zea mays). Weed Sci., v. 45, n. 4, p. 557-563, 1997.

BUHLER, D. D.; GUNSOLUS, J. L.; RALSTON, D. F. Integrated weed management techniques to reduce herbicide inputs in soybean. Agron. J., v. 84, n. 6, p. 973-978, 1992.

CARRANZA, P.; SAAVEDRA, M.; GARCIA-TORRES, L. Competition between Ridolfia segetum and sunflower. Weed Res., v. 35, n. 5, p. 369-375, 1995.

CHARLES, G. W.; MURISON, R. D.; HARDEN, S. Competition of noogora burr (Xanthium occidentale) and fierce thornapple (Datura ferox) with cotton (Gossypium hirsutum). Weed Sci., v. 46, n. 4, p. 442-446, 1998.

COBLE, H. D.; MORTENSEN, D. A. The threshold concept and its application to weed science. Weed Technol., v. 6, n. 1, p. 191-195, 1992.

COUSENS, R. An empirical model relating crop yield to weed and crop density and a statistical comparison with other models. J. Agric. Sci., v. 105, n. 3, p. 513-521, 1985.

CZAPAR, G. F.; CURRY, M. P.; WAX, L. M. Grower acceptance of economic thresholds for weed management in Illinois. Weed Technol., v. 11, n. 4, p. 828-831, 1997.

DEVLIN, D. L.; LONG, J. H.; MADDUX, L. D. Using reduced rates of postemergence herbicides in soybeans (Glycine max). Weed Technol., v. 5, n. 4, p. 834-840, 1991.

DIELEMAN, A. et al. Decision rules for postemergence control of pigweed (Amaranthus spp.) in soybean (Glycine max). Weed Sci., v. 44, n. 1, p. 126-132, 1996.

DOYLE, C. J. A review of the use of models of weed control in integrated crop protection. Agric. Ecos. \& Env., v. 64 , n. 2, p. 165-172, 1997.

EMPRESA BRASILEIRA DE PESQUISA AGROPECUÁRIA - EMBRAPA. Centro Nacional de Pesquisa de Solos. Sistema brasileiro de classificação de solos. Brasília: 1999. 412 p. 
JONES, R. E.; MEDD, R. W. Economic thresholds and the case for longer term approaches to population management of weeds. Weed Technol., v. 14, n. 2, p. 337-350, 2000.

KING, R. P. et al. Bioeconomic modeling to simulate weed control strategies for continuous corn (Zea mays). Weed Sci., v. 34, n. 6, p. 972-979, 1986.

KLINGAMAN, T. E.; KING, C. A.; OLIVER, L. R. Effect of application rate, weed species, and weed stage of growth on imazethapyr activity. Weed Sci., v. 40, n. 2, p. 227-232, 1992.

KNEZEVIC, S. Z.; HORAK, M. J.; VANDERLIP, R. L. Relative time of redroot pigweed (Amaranthus retroflexus $\mathrm{L}$.) emergence is critical in pigweed-sorghum [Sorghum bicolor (L.) Moench] competition. Weed Sci., v. 45, n. 4, p. 502508, 1997.

KROPFF, M. J.; SPITTERS, J. T. A simple model of crop loss by weed competition from early observations on relative leaf area of the weeds. Weed Res., v. 31, n. 2, p. 97-105, 1991.

LINDQUIST, J. L. et al. Economic importance of managing spatially heterogeneous weed populations. Weed Tech., v. 12 , n. 1, p. $7-13,1998$.

LINDQUIST, J. L.; KROPFF, M. J. Applications of an ecophysiological model for irrigated rice (Oryza sativa)-Echinochloa competition. Weed Sci., v. 44, n. 1, p. 52-56, 1996.
McDONALD, A. J.; RIHA, S. J. Model of crop:weed competition applied to maize:Abutilon theophrasti interactions. II. Assessing the impact of climate: implications for economic thresholds. Weed Res., v. 39, n. 5, p. 371-381, 1999.

ONOFRI, A.; TEI, F. Competitive ability and threshold levels of three broadleaf weed species in sunflower. Weed Res., v. 34, n. 6, p. 471-479, 1994.

PESTER, T. A. et al. Secale cereale interference and economic thresholds in winter Triticum aestivum. Weed Sci., v. 48, n. 6, p. 720-727, 2000.

RIZZARDI, M. A. Nível de dano econômico para tomada de decisão no controle de picão-preto (Bidens spp.) e guanxuma (Sida rhombifolia L.) na cultura da soja. Porto Alegre: UFRGS, 2002. 176p. Tese (Doutorado em Fitotecnia - Plantas de Lavoura) - Universidade Federal do Rio Grande do Sul, 2002.

SAS - INSTITUTE. Institute Statistical Analysis System. User's guide: version 6. 4.ed. Cary: SAS Institute, 1989. $846 \mathrm{p}$.

WEAVER, S. E. Size-dependent economic thresholds for three broadleaf weed species in soybeans. Weed Technol. v. 5 , n. 3, p. 674-679, 1991. 